\title{
Prevalence and Phylogenetic Analysis of Babesia ovis Isolated from Sheep and Goats in Erbil Province, Kurdistan Region- Iraq
}

\author{
Zuber I. Hassan \\ Department of Medical Laboratory Techniques, Shaqlawa Technical College, Erbil Polytechnic University, Erbil, Kurdistan Region - Iraq
}

\begin{abstract}
*Corresponding author:
Zuber I. Hassan, Department

of Medical Laboratory

Techniques, Shaqlawa

Technical College, Erbil

Polytechnic University, Erbil,

Kurdistan Region - F.R. Iraq.

E-mail: zuberismail@epu.

edu.iq
\end{abstract}

Received: 15 April 2020

Accepted: 19 July 2020

Published: 30 December 2020

\section{DOI}

10.25156/pti.v10n2y2020.pp98-104

\section{A B S T R A C T}

A total of 143 blood smears were obtained from sheep and goats $(n=98)$ and $(n=45)$, respectively, by jugular venipuncture between February 2019 and December 2019. Samples were examined for parasite occurrences. Results reveal that the prevalence of infection by the parasite was $12.24 \%$ and $11.11 \%$, respectively (microscopically), while $20.41 \%$ sheep and $17.78 \%$ goats (molecular-based identification using $18 \mathrm{~S}$ SSU rRNA sequence). Both methods revealed the specificity and sensitivity of the diagnostic assays. Phylogenetic analysis of Babesia ovis (MN309736-MN309745) displays that the pathogens identified in this study are clustered together, which indicating similar molecular characteristics. Overall, these results provide a better understanding that Babesiosis is highly prevalent in the study area and continuous monitoring of tick-borne pathogen in sheep and goats are essentially required in Erbil Province.

Keywords: 18S SSU rRNA; Babesiosis; Erbil province; Phylogeny; Tick-borne

\section{INTRODUCTION}

Babesia parasites are tick-borne diseases and obligate intraerythrocytic protozoa belonging to the phylum Apicomplexa (Lee et al., 2018), capable of invading a wide range of vertebrate hosts, including animals and human, subsequently leading to serious economic problems for the livestock industry throughout tropical and subtropical regions of the world (Munkhjargal et al., 2016). Babesia ovis, Babesia motasi, and Babesia crassa are recognized as the species causing ovine Babesiosis. The first one is highly pathogenic to sheep and goats with mortality rates of $30-50 \%$, while the other two species are non-pathogenic or less pathogenic (Zangana and Naqid, 2011 and M'ghirbi et al., 2013). The infected animal recovers after a period of 5-8 days or dies (Razmi et al., 2003 and Ijaz et al., 2013). The first clinical signs are acute pneumonia (cough and mucus production), the susceptibility depends on the breed, but they often have concurrent infections (Rahbari et al., 2008 and Hassan, 2011). The body temperature rises before the onset of overt parasitemia (Hassan, 2011). Severe anemia, hemoglobinuria may occur for 5 days, followed by death. At the same time, severe leucopenia develops (Rahbari et al., 2008; Hassan, 2011 and Zangana and Naqid, 2011).

Giemsa-stained blood smears as a laboratory diagnosis is used in small ruminant piroplasmosis. However, species identification by microscopy is difficult because different parasites share a similar morphology, and if mixed infections occur. Furthermore, identification can be difficult in carrier animals where the presence of parasites is low and even in acute cases at the onset of the disease (M'ghirbi et al., 2013 and Hasheminasab et al., 2018). The advanced biological techniques such as polymerase chain reaction (PCR) could be used for identification of Babesia spp. with a high degree of sensitivity and useful for the identification and classification of several hemoparasites (Habibi et al., 2004; Ahmed et al., 2006; Chen et al., 2014; Naderi et al., 2017 and Niu et al., 2017).

The aim of the study was to detect and identify Babesia spp. infecting sheep and goats in Erbil Province, using microscopic and PCR. In blood, the parasite cannot easily be diagnosed by examination of stained blood film and negative microscopic examination does not exclude the possibility of infection and to determine their phylogenetic relationships to related species based on $18 \mathrm{~S}$ rRNA gene sequence analysis.

\section{MATERIALS AND METHODS}

\section{Study Area}

This study was carried out in the Veterinary Department, Shaqlawa Technical Institute, and Paitaxt Technical 
Institute, Erbil-Kurdistan. The sheep and goats maintained under a traditional extensive husbandry system (kept on pasture and housed at night). Acaricide treatment is usually conducted two in the year (spring and autumn).

\section{Collection of Blood Samples}

One hundred forty-three whole blood samples were collected from sheep $(n=98)$ and goats $(n=45)$ by jugular venipuncture between February 2019 and December 2019. At the time of blood sample collection, the animals were manually examined for the presence of ticks.

\section{Microscopic Examination}

The thin blood smears were prepared immediately after the collection of blood samples and fixed in absolute methanol for 5 min and stained by Giemsa stain diluted at $10 \%$ with a buffer solution for $30 \mathrm{~min}$. Slides were screened under oil immersion ( $\times 100$ magnification) for the presence of intraerythrocytic piroplasms (Rahbari et al., 2008 and Shayan et al., 2008). The morphological and biometrical parameters such as the shape and location of parasite in any infected erythrocyte have been considered for differential diagnosis (Haghi et al., 2013).

\section{DNA Analysis and PCR Amplification}

DNA was extracted using Qiagen DNA extraction kits, according to the manufacturer's instructions. For amplification of Babesia spp., the usual primers forward (5-TGGGCAGGACCT'TGGTTCTTCT-3) and reverse (5- CCGCGTAGCGCCGGCTAAATA -3) were used to amplify 549bp sequence of the $18 \mathrm{~S}$ SSU rRNA gene (Ringo et al., 2018). The PCR was performed using AB Applied Biosystems Thermocycler (Veriti 96 Well Thermal Cycler - Singapore). The amplification reaction mixture $(25 \mu \mathrm{l})$ consisted of $12.5 \mu \mathrm{l}$ of (2X) Go-Tag master mix, $2.5 \mu \mathrm{l}$ of each primer (forward and reverse), $2.5 \mu \mathrm{l}$ of template DNA, and $5 \mu$ nuclease-free water. The reaction mixtures were subjected to an initial denaturation step of $15 \mathrm{~min}$ at $95^{\circ} \mathrm{C}$, followed by 38 cycles of denaturation at $95^{\circ} \mathrm{C}$ for the $30 \mathrm{~s}$, annealing at $62^{\circ} \mathrm{C}$ for $30 \mathrm{~s}$, and elongation at $72^{\circ} \mathrm{C}$ for $1 \mathrm{~min}$. Amplification was completed by a further $5 \mathrm{~min}$ step at $72^{\circ} \mathrm{C}$. Negative and positive controls were included in each amplification assay. The Conventional PCR products were visualized through ultraviolet transillumination in 1.5\% Agarose gel, following electrophoresis and staining with ethidium bromide. The amplified products were commercially sequenced in both directions (BMRg, Padua, Italy) and the generated sequences were examined using Accelrys Gene 2.5 program (Accelrys, Cambridge, $\mathrm{UK}$ ) and compared against the NCBI database through the use of BLAST algorithm (http://www.ncbi.nlm.nih.gov/BLAST/).

\section{Phylogenetic Analysis}

Multiple sequence alignments and sequence similarities were calculated using the Clustal W (Thompson et al., 1994) and the identity matrix options of BioEdit (Hall, 1999), respectively. Phylogenetic analyses were inferred by the neighbor-joining method using MEGA version 6 software.

\section{Nucleotide Sequence Accession Numbers}

Babesia sequences identified in this study were deposited in the GenBank database of the National Center for Biotechnology Information (https:/ / submit.ncbi.nlm.nih. gov/). The GenBank accession numbers were assigned to the following genes: MN309736-MN309745.

\section{RESULTS}

Out of the 143 blood smears examined, 12 samples $(8.39 \%)$ were positive for Babesia in sheep and 5 samples (3.5\%) were positive in goats, respectively, as showed in Table 1.

All samples positive with microscopic examination of blood smears were also positive with the PCR test. Eight cases in sheep and three cases in goats became positive by the molecular method but were negative by the microscopic method. The performance of both tests in terms of detection of positive cases has been compared in Table 1. Statistically ( $t$-test statistics) showed the significant difference between the performance of the PCR technique and microscopy for the diagnosis of hemoparasites.

Twenty-eight of 143 samples showed amplification of a 549-bp fragment with the primer forward (5-TGGGCAGGACCT'TGGT'TCTTC'T-3) and reverse (5- CCGCGTAGCGCCGGCTAAATA -3), specific for Babesia spp. Among the 28 samples (20 sheep and 8 goats), respectively, were positive for $B$. ovis by PCR.

All the amplicons of Babesia spp. from sheep and goats were chosen for genetic analysis. The comparison of the $18 \mathrm{~S}$ SSU rRNA sequence in sheep shows $100 \%$ homology between (Mn309736 and Mn309741) with the recently reported sequence (KY283960) from Turkey

Table 1: Prevalence of Babesiosis among the examined host, using the different diagnostic techniques

\begin{tabular}{lccccc} 
Host type & $\begin{array}{c}\text { No. of examined sample } \\
\text { (clinically affected) }\end{array}$ & $\begin{array}{c}\text { Positive sample } \\
\text { microscopically }\end{array}$ & Prevalence (\%) & $\begin{array}{c}\text { Positive sample by molecular- } \\
\text { based identification }\end{array}$ & $\begin{array}{c}\text { Prevalence (\%) } \\
\text { Sheep }\end{array}$ \\
Goats & 98 & 12 & 12.24 & 20 & 20.41 \\
Total & 45 & 5 & 11.11 & 8 & 17.78 \\
\hline
\end{tabular}


(Bilgic et al., 2017), as shown in Figure 1 and have one nucleotide difference (Mn309738 and Mn309740) in 165 (A to $G$ ), additionally have two nucleotide difference with (Mn309737) in 96 and 165 (A to G). The B. ovis sequence described in this study from Erbil (Mn309739) had three nucleotide differences. As well as, Figure 2 shows the comparison of $B$. ovis sequences accession number (Mn309742, Mn309743, Mn309744, and Mn309745) in goats with the accession number (KY581552) in Iran. A phylogenetic tree of Babesia was constructed from the 18S $r R N A$ gene sequences of our amplicons and those available in GenBank [Figures 3 and 4].

\section{DISCUSSION}

B. ovis causing Babesiosis is the most frequent pathogen in sheep and goats with the rate $12.24 \%$ and $11.11 \%$, respectively, using microscopical examination, these agreed with Hassan (2011), who showed that the rate of infection in sheep was (11.1\%) from a total of 360 sheep in Iraq and Naderi et al. (2017) who was recorded 38 (9.9\%) from a total 306 sheep in Iran because this observation could participate with veterinary service (both government and private) in this region to eradicate the vector by dipping of the animals twice in the year. The present results disagreed with that previously mentioned by Esmaeilnejad et al. (2015) in Iran, that Babesia spp. was 52 (18.5\%) from a total of 280 samples, and with that of Hasan (2013) who revealed that the infection rate $(22.1 \%)$ of Babesia spp. in sheep from a total of 384 in Syria. Furthermore, Shahzad et al., 2013, who was showed that 32 (16\%) were positive from a total of 200 samples in Pakistan. Such variation in the prevalence may be attributed to several factors, including geographical variation and consequently,

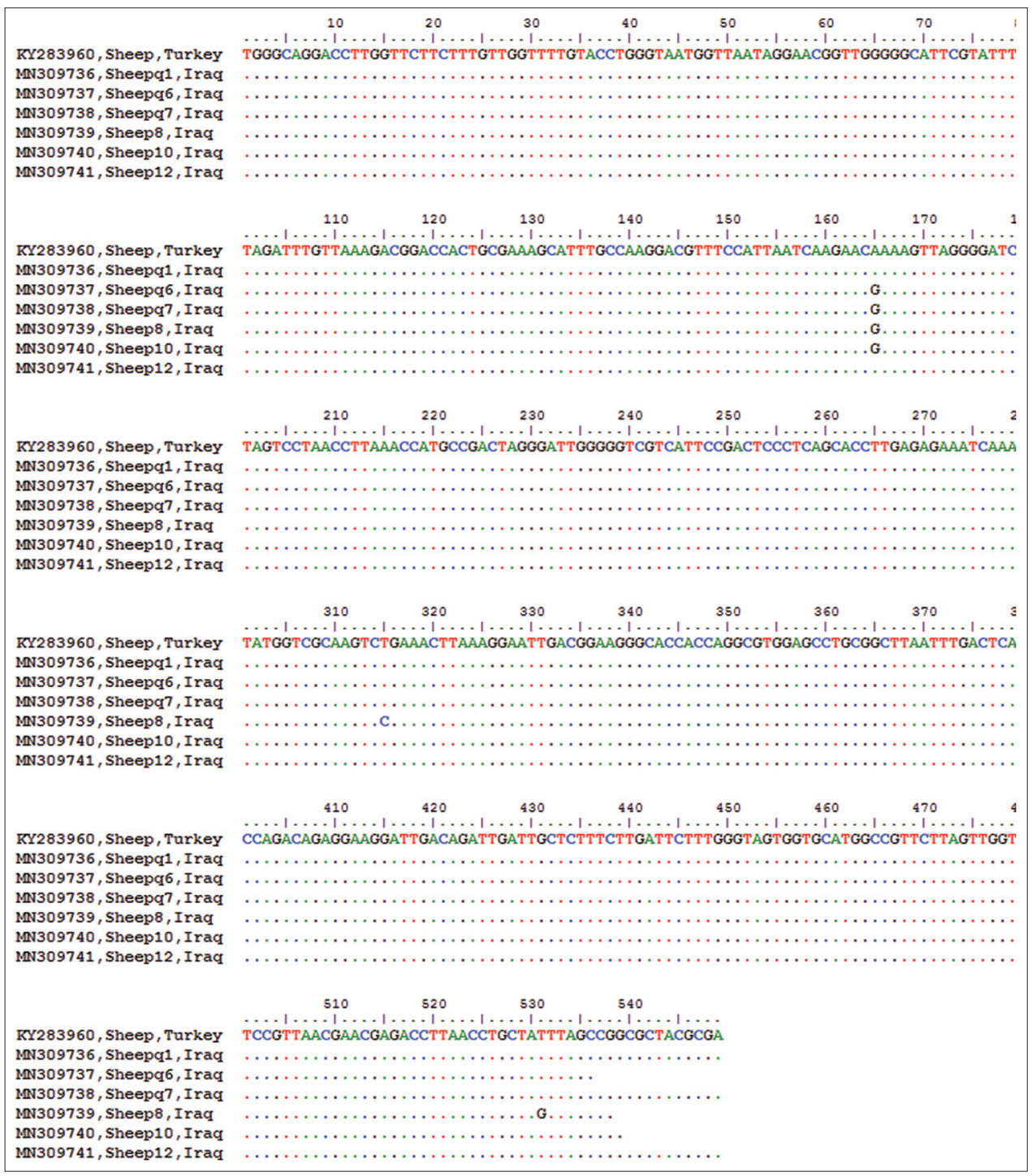

Figure 1: Parts of the sequence results of cloned Babesia ovis positive samples in sheep no. 1, 6, 7, 8, 10, and 12 were compared with published sequences available in the NCBI database (accession no. KY283960) 


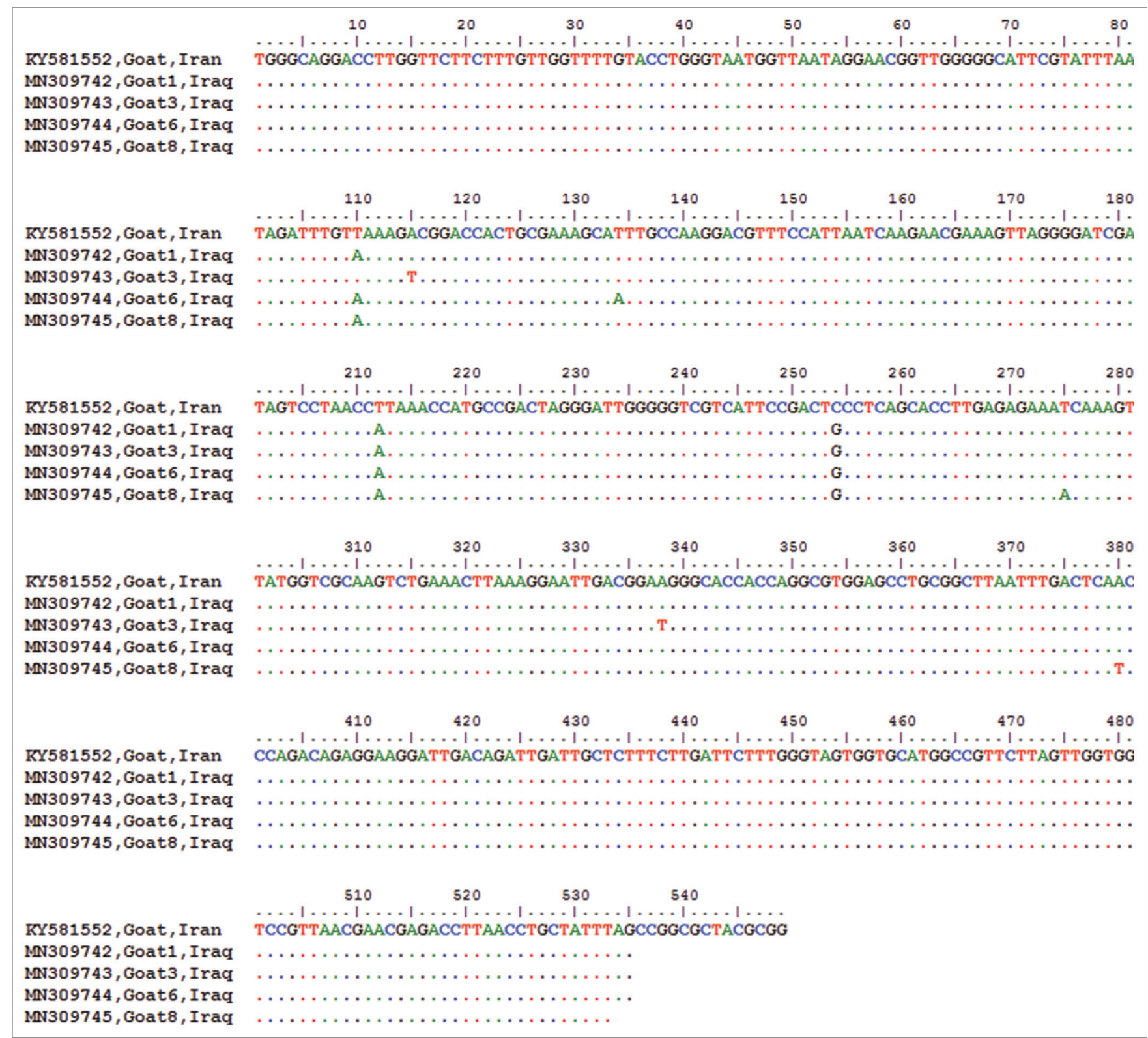

Figure 2: Parts of the sequence results of cloned Babesia ovis positive samples in goats no. 1, 3, 6, and 8 were compared with published sequences available in the NCBI database (accession no. KY581552)

difference in climatic conditions that affect the vector activity, examined regions are neighboring countries and experimental methods might explain the difference in the results. In goat, of the 45 blood smears examined, 5 (11.11\%) samples were positive for Babesia spp., this agreed with Hassan, 2011, who revealed that the rate of infection was $13.5 \%$ from a total 205 goats in Erbil Province and Abdul-Hassan and Ali (2016) revealed that 8/68 (11.7\%) cases of examined goats were given positive result in ALQadisiya province. Esmaeilnejad et al., 2015, showed that $12.2 \%(15 / 122)$ were infected with B. ovis in goat. As well as, our result partially agreed with Sulaiman et al. (2010) in Mosul, who showed that the rate of infection was $15.4 \%$ from a total 175 goat and Iqbal et al. (2011) revealed that the infection rate $16(24 \%)$. However, disagreed with Abdullah and Mohammed (2014), who showed that, the rate of infection 16/25 (64\%) from a total of 25 goats in Sulaimani city. Furthermore, Naderi et al. (2017), in Iran, explained from a total of 51 sample $9(2.3 \%)$ goats were infected.

Classically microscopic examination of Giemsa-stained blood smears is used to detect Babesia infections (Abdullah and Mohammed, 2014 and Esmaeilnejad et al., 2015). However, this method has a low sensitivity and requires expertise because these parasites have similar morphology and therefore, different species may be confused (Bilgic et al., 2017 and Gholamreza et al., 2017). In this study, 


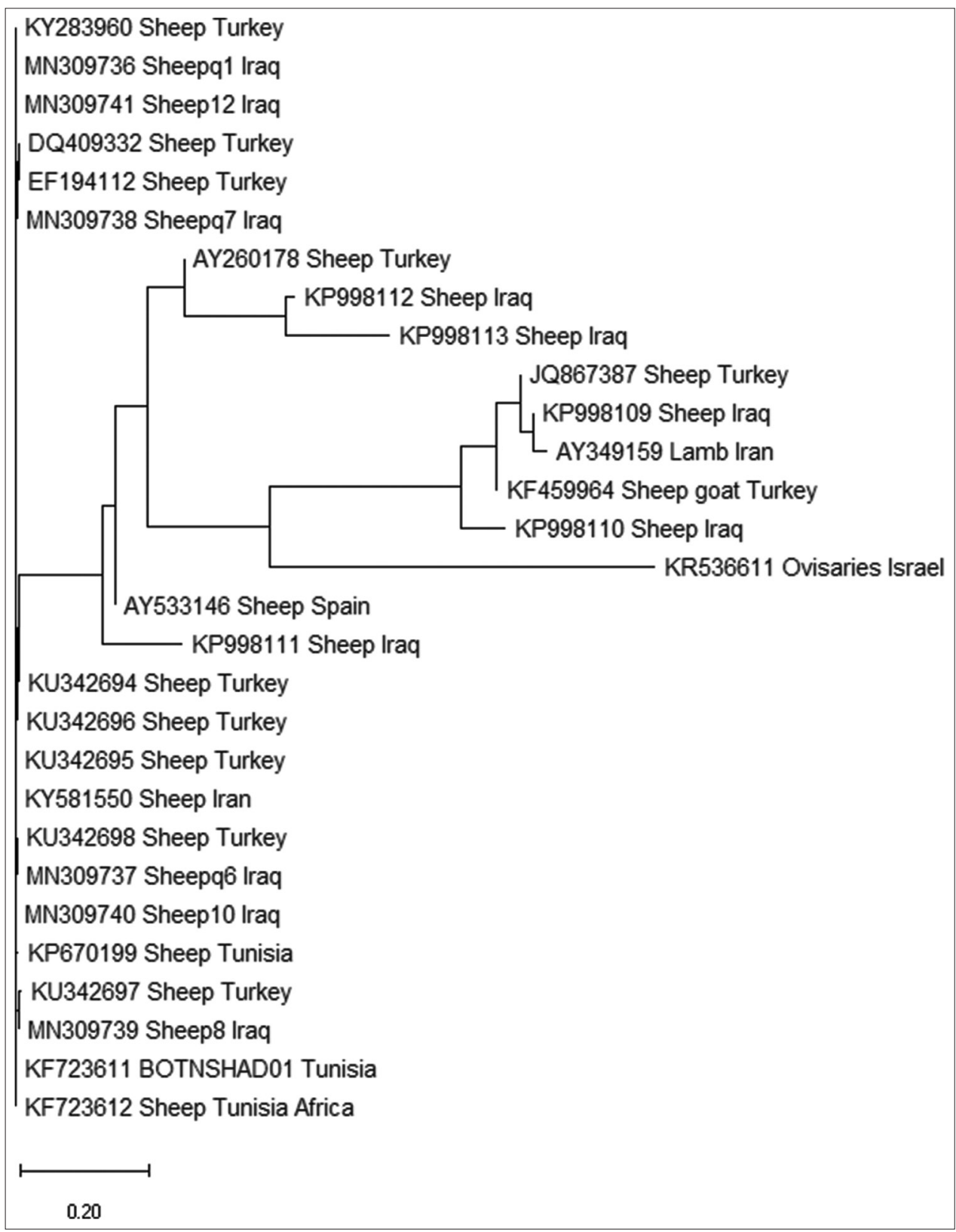

Figure 3: Phylogenetic positioning of Babesia ovis isolated from sheep according to the sequence of $18 \mathrm{~S}$ SSU rRNA constructed in MEGA ver.7 using the neighbor-joining method

molecular epidemiology was used to diagnose this disease in sheep and goats from Erbil Province. B. ovis was detected in the sampling region, suggesting that they may be important tick-borne diseases because the molecular prevalence of B. ovis in small ruminants is a powerful tool and practical assay since it can detect extremely low parasitemia rates and simultaneously identify Babesia species (Chisua et al., 2019); moreover, the microscopic technique does not detect carrier animals with very low parasitemia (Rjeibi et al., 2014).

The rate of infection was higher $20(20.41 \%)$ in sheep by molecular method than goats $8(9.04 \%)$. It was stated that B. ovis induces symptoms more frequently in sheep than goats (Bilgic et al., 2017) and the result agreed with (Aktas et al., 2007 and Iqbal et al., 2011) revealed that prevalence rate of B. ovis infection in sheep was higher than in goats in Turkey and Pakistan, respectively. Figure 3 revealed that a phylogenetic analysis of the partial $18 \mathrm{~S} \mathrm{rRNA}$ sequence was performed by aligning the six sequence types obtained in this study in sheep with selected Babesia sequences (AY260178, DQ409332, EF194112, JQ867387, KF459964, KP998109- KP998113, KU342694-KU342698, AY349159, KY581550, KR536611, AY533146, KP670199, KF723612, and KF723611) (Habibi et al., 2004; Altay et al., 2007; Rjeibi et al., 2014; Erster et al., 2016; Rjeibi et al., 2016; Ozubek and Aktas, 2017; and Zhou et al., 2017). 


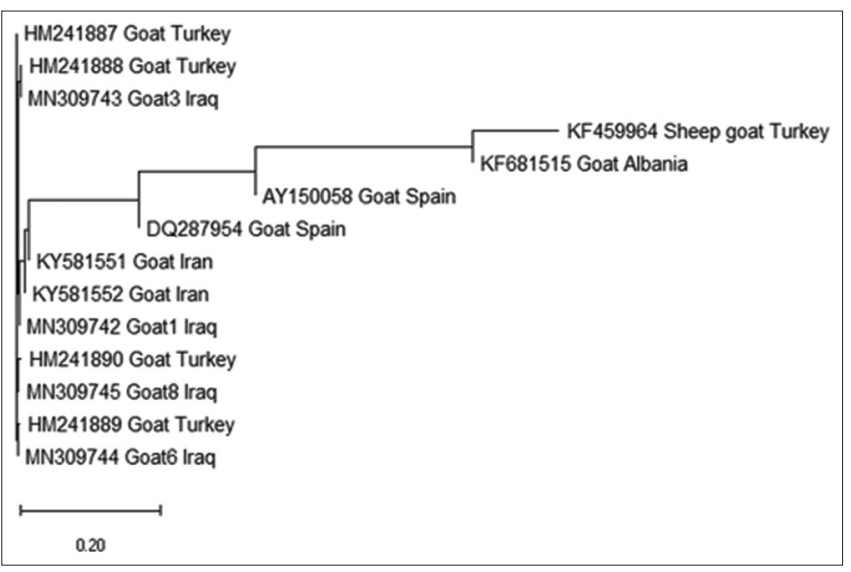

Figure 4: Phylogenetic positioning of Babesia ovis isolated from goats according to the sequence of 18S SSU rRNA constructed in MEGA ver.7 using the neighbor-joining method

Furthermore, in goats [Figure 4] show phylogenetic analysis with the selected sequences in gene bank (HM241887- HM241890, KF459964, KF681515, KY581552, KY581551, AY150058, and DQ287954) (Criado et al., 2006; Rjeibi et al., 2014; Zhou et al., 2017; and Sevinc et al., 2018). The phylogram showed that B. ovis from this study was placed in the same clade with all other sequences in this phylogenetic tree. Similar results were reported in Turkey and Iran where small ruminants were only infected by B. ovis (Altay et al., 2007 and Esmaeilnejad et al., 2014). As well as, the long branch length revealed that B. ovis obtained in this study has an increased degree of genetic divergence concerning the other selected sequences obtain in a gene bank, which suggests that geographical location could be the reason for this difference.

\section{CONCLUSION}

This study has detected the presence of B. ovis in small ruminants in Erbil provinces. The sheep are more sensitive than goats to infection by using microscopic and PCR. A second method is a powerful tool, high sensitivity, and practical assay since it can detect extremely low parasitemia rates and simultaneously identify Babesia species than the first one. Sequencing and phylogenetic analysis showed that B. ovis in Erbil was not different from the pathogens in other animals from geographically distinct regions. These data provide important information about the incidence of $B$. ovis in sheep and goat and its benefits for managing and controlling programs of the disease.

\section{ACKNOWLEDGMENTS}

The author is grateful to all staff of Shaqlawa Technical Institute during sampling and methodological procedures and also I would like to thank Erbil Polytechnic University for the financial support of this study.

\section{REFERENCES}

Abdul-Hassan, N. S. and M. J. Ali. 2016. An investigation of Babesia spp. in goats in AL-Qadisiya Province. AL Qadisiya J. Vet. Med. Sci. 15(1): 77-80.

Abdullah, S. H. and A. A. Mohammed. 2014. Babesiosis of small ruminants in Sulaimani city Kurdistan-Iraq. AL Qadisiya J. Vet. Med. Sci. 13(2): 39-43.

Ahmed, J. S., J. Luo, L. Schnittger, U. Scitzer, F. Jongejan and H. Yin. 2006. Phylogenetic position of small-ruminant infecting piroplasms. Ann. N. Y. Acad. Sci. 1081; 498-504.

Aktas, M., K. Altay and N. Dumanli. 2007. Determination of prevalence and risk factors for infection with Babesia ovis in small ruminants from Turkey by polymerase chain reaction. Parasitol. Res. 100(4): 797-802.

Altay, K., N. Dumanli and M. Aktas. 2007. Molecular identification, genetic diversity and distribution of Theileria and Babesia species infecting small ruminants. Vet. Parasitol. 147: 161-165.

Bilgic, H. B., S. Bakırcı, O. Kose, A. H. Unlu, S. Hacılarlıglu, H. Eren, W. Weir and T. Karagenc. 2017. Prevalence of tick-borne haemoparasites in small ruminants in Turkey and diagnostic sensitivity of single-PCR and RLB. Parasit. Vectors. 10(1): 211.

Chen, Z., Q. Liu, J. Liu, B. Xu, S. Lv, S. Xia and X. Zhou. 2014. Tickborne pathogens and associated co-infections in ticks collected from domestic animals in central China. Parasit. Vectors. 7: 237.

Chisua, V., A. Albertib, R. Zobbab, C. Foxia and G. Masala. 2019. Molecular characterization and phylogenetic analysis of Babesia and Theileria spp. in ticks from domestic and wild hosts in Sardinia. Acta Trop. 196: 60-65.

Criado, A., J. Martinez, A. Buling, J.C. Barbara, S. Merino, R. Jefferies and P. J. Irwin. 2006. New data on epizootiology and genetics of piroplasms based on sequences of small ribosomal subunit and cytochrome b genes. Vet. Parasitol. 142: 238-247.

Erster, O., A. Roth, R. Wolkomirsky, B. Leibovich, I. Savitzky and V. Shkap. 2016. Transmission of Babesia ovis by different Rhipicephalus bursa developmental stages and infected blood injection. Ticks Tick Borne Dis. 7: 13-19.

Esmaeilnejad, B., M. Tavassoli, S. Asri-Rezaei, B. Dalir-Naghadeh, K. Mardani and G. Jalilzadeh-Amin. 2014. PCR-based detection of Babesia ovis in Rhipicephalus bursa and small ruminants. J. Parasitol. Res. 2014: 294704.

Esmaeilnejad, B., M. Tavassoli, S. Asri-Rezaei, B. Dalir-Naghadeh, K. Mardani, M. Golabi, J. Arjmand, A. Kazemnia and G. Jalilzadeh. 2015. Determination of prevalence and risk factors of infection with Babesia ovis in small ruminants from West Azerbaijan Province, Iran by polymerase chain reaction. J. Arthropod. Borne Dis. 9(2): 246-252.

Gholamreza, S., M. Somaieh, S. Roya, B. Alireza, A. Ghazale and B. Yasin. 2017. First detection of Babesia ovis in Dermacentor spp in Ardabil area, Northwest of Iran. J. Vector Borne Dis. 54(3): 277-281.

Habibi, G. R., R. Hashemi-Fesharki and N. Bordbar. 2004. Detection of Babesia ovis using polymerase chain reaction. Arch. Raz Inst. 57: 1-10.

Haghi, S. M. M., M. Fakhar, M. Sharif, A. Paghe, M. Sharbatkhori, R. Tavakoli and G. Shirzad. 2013. Molecular identification of ovine Babesia spp. in North of Iran. Res. Mol. Med. 1(1): 35-39.

Hall, T. A. 1999. BioEdit: A user-friendly biological sequence alignment 
editor and analysis program for Windows 95/98/NT. Nucleic Acids Symp. Ser. 41: 95-98.

Hasan, S. 2013. Seasonal prevalence of Babesia in sheep in South Syria. Arab J. Arid Environ. 6(2): 21-25.

Hasheminasab, S. S., P. Moradi and I. Wright. 2018. A four year epidemiological and chemotherapy survey of babesiosis and theileriosis, and tick vectors in sheep, cattle and goats in Dehgolan, Iran. Ann. Parasitol. 64(1): 43-48.

Hassan, Z. I. 2011. Epidemiological study of babesiosis in sheep and goats in Shaqlawa District, Erbil Governorate, Iraq. J. Koya Univ. 20: 157-172.

Ijaz, M., A. Rehman, M. M. Ali, M. Umair, S. Khalid, K. Mehmood and A. Hanif. 2013. Clinico-epidemiology and therapeutical trials on babesiosis in sheep and goats in Lahore, Pakistan. J. Anim. Plant Sci. 23(2): 666-669.

Iqbal, F., M. Ali, M. Fatima, S. Shahnawaz, S. Zulifqar, R. Fatima, R. S. Shaikh, A. S. Shaikh, M. Aktas and M. Ali. 2011. A study on the determination of risk factors associated with babesiosis and prevalence of Babesia sp., by PCR amplification, in small ruminants from Southern Punjab (Pakistan). Parasite. 18: 229-234.

Lee, S., E. Mossaada, A. M. Ibrahimd, A. A. Ismailc, P. F. A. Moumounia, M. Liua, A. E. Ringoa, Y. Gaoa, H. Guoa, J. Lia, A. Efstratioua, P. Musinguzia, T. E. E. Angarae, K. Suganuma, N. Inouef and X. Xuan. 2018. Detection and molecular characterization of tickborne pathogens infecting sheep and goats in Blue Nile and West Kordofan states in Sudan. Ticks Tick Borne Dis. 9(3): 598-604.

M'ghirbi, Y., A. Ros-García, P. Iribar, A. Rhaim, A. Hurtado and A. Bouattour. 2013. A molecular study of tick-borne haemoprotozoan parasites (Theileria and Babesia) in small ruminants in Northern Tunisia. Vet. Parasitol. 198: 72-77.

Munkhjargal, T., G. O. Aboge, A. Ueno, M. Aboulaila, N. Yokoyama and I. Igarashi. 2016. Identification and characterization of profilin antigen among Babesia species as a common vaccine candidate against babesiosis. Exp. Parasitol. 166: 29-36.

Naderi, A., H. Nayebzadeh and S. Gholami. 2017. Detection of Babesia infection among human, goats and sheep using microscopic and molecular methods in the city of Kuhdasht in Lorestan Province, West of Iran. J. Parasit. Dis. 41(3): 837-842.

Niu, Q., Z. Liu, J. Yang, S. Gao, Y. Pan, G. Guan, J. Luo and H. Yin. 2017. Genetic characterization and molecular survey of Babesia $s p$. Xinjiang infection in small ruminants and ixodid ticks in China. Infect. Genet. Evol. 49: 330-335.

Ozubek, S. and M. Aktas. 2017. Molecular evidence of a new Babesia sp. in goats. Vet. Parasitol. 233: 1-8.

Rahbari, S., S. Nabian, Z. Khaki, N. Alidadi and J. Ashrafihelan. 2008. Clinical, haematologic and pathologic aspects of experimental ovine babesiosis in Iran. Iran. J. Vet. Res. 9(22): 59-64.
Razmi, G.R., A. Naghibi, M. R. Aslani, K. Dastjerdi and H. Hosseini. 2003. An epidemiological study on Babesia infection in small ruminants in Mashhad suburb, Khorasan Province, Iran. Small Rumin. Res. 50(1-2): 39-44.

Ringo, A.E., P. F. A. Moumounia, M. Taioe, C. Jirapattharasate, M. Liu, G. Wang, Y. Gao, H. Guo, S. Lee, W. Zheng, A. Efstratiou, J. Li, N. Inoue, H. Suzuki, O. Thekisoe and X. Xuan. 2018. Molecular analysis of tick-borne protozoan and rickettsial pathogens in small ruminants from two South African Provinces. Parasitol. Int. 67(2): 144-149.

Rjeibi, M. R., M. A. Darghouth and M. Gharbi. 2016. Prevalence of Theileria and Babesia species in Tunisian sheep. Onderstepoort J. Vet. Res. 83(1): a1040.

Rjeibi, M.R., M. Gharbi, M. Mhadhbi, W. Mabrouk, B. Ayari, I. Nasfi, M. Jedidi, L. Sassi, M. Rekik and M. A. Darghouth. 2014. Prevalence of piroplasms in small ruminants in North-West Tunisia and the first genetic characterization of Babesia ovis in Africa. Parasite. 21: 23.

Sevinc, F., M. Zhou, S. Cao, O. Ceylan, M. F. Aydin, M. Sevinc and X. Xuan. 2018. Haemoparasitic agents associated with ovine babesiosis: A possible negative interaction between Babesia ovis and Theileria ovis. Vet. Parasitol. 15(252): 143-147.

Shahzad, W., N. O. Haider, A. H. Mansur, R. Munir, M. S. Saghar and M. H. Mushtaq. 2013. Prevalence and molecular diagnosis of Babesia ovis and Theileria ovis in Lohi sheep at livestock experiment station (LES), Bahadurnagar, Okara, Pakistan. Iran. J. Parasitol. 8(4): 570-578.

Shayan, P., E. Hooshmand, S. Nabian and S. Rahbari. 2008. Biometrical and genetical characterization of large Babesia ovis in Iran. Parasitol. Res. 103: 217-221.

Sulaiman, E. G., S. H. Arslan, Q. T. Al-Obaidi and E. Daham. 2010. Clinical, haematological and biochemical studies of babesiosis in native goats in Mosul. Iraqi J. Vet. Sci. 24(1): 31-35.

Thompson, J. D., D. G. Higgins and T. J. Gibson. 1994. CLUSTAL $\mathrm{W}$ : Improving the sensitivity of progressive multiple sequence alignment through sequence weighting, position-specific gap penalties and weight matrix choice. Nucleic Acids Res. 22: 46734680.

Zangana, I. K. and I. A. Naqid. 2011. Prevalence of piroplasmosis (theileriosis and babesiosis) among goats in Duhok Governorate. Al Anbar J. Vet. Sci. 4(2): 50-57.

Zhou, M., S. Cao, F. Sevinc, M. Sevinc, O. Ceylan, S. Ekici, C. Jirapattharasate, P. F. Moumouni, M. Liu, G. Wang, A. Iguchi, P. Vudriko, H. Suzuki and X. Xuan. 2017. Molecular detection and genetic characterization of Babesia, Theileria and Anaplasma amongst apparently healthy sheep and goats in the central region of Turkey. Ticks Tick Borne Dis. 8(2): 246-252. 